\title{
Macrophages use different internalization mechanisms to clear apoptotic and necrotic cells
}

\author{
DV Krysko ${ }^{1,2}$, G Denecker ${ }^{2}$, N Festjens ${ }^{2}$, S Gabriels ${ }^{1}$, \\ E Parthoens $^{3}$, K D'Herde $^{1,4}$ and P Vandenabeele ${ }^{\star, 2,4}$ \\ 1 Department of Human Anatomy, Embryology, Histology and Medical Physics, \\ Ghent University, Ghent 9000, Belgium \\ 2 Molecular Signalling and Cell Death Unit, Department of Molecular Biomedical \\ Research, VIB - Ghent University, Ghent 9052, Belgium \\ ${ }^{3}$ Microscopy Core Facility, Department for Molecular Biomedical Research, VIB \\ - Ghent University, Ghent 9052, Belgium \\ ${ }^{4}$ These authors share senior authorship. \\ * Corresponding author: P Vandenabeele, Molecular Signalling and Cell Death \\ Unit, Department for Molecular Biomedical Research, VIB - Ghent University, \\ Technologiepark 927, 9052 Ghent, Belgium. Tel: 32-9-33-13-760; \\ Fax: 32-9-33-13-609; E-mail: Peter.Vandenabeele@dmbr.UGent.be
}

Received 13.7.05; revised 24.1.06; accepted 13.2.06; published online 21.4.06 Edited by B Zhivorivsky

\section{Abstract}

The present study characterized two different internalization mechanisms used by macrophages to engulf apoptotic and necrotic cells. Our in vitro phagocytosis assay used a mouse macrophage cell line, and murine L929sAhFas cells that are induced to die in a necrotic way by TNFR1 and heat shock or in an apoptotic way by Fas stimulation. Scanning electron microscopy (SEM) revealed that apoptotic bodies were taken up by macrophages with formation of tight fitting phagosomes, similar to the 'zipper'-like mechanism of phagocytosis, whereas necrotic cells were internalized by a macropinocytotic mechanism involving formation of multiple ruffles directed towards necrotic debris. Two macropinocytosis markers (Lucifer Yellow (LY) and horseradish peroxidase (HRP)) were excluded from the phagosomes containing apoptotic bodies, but they were present inside the macropinosomes containing necrotic material. Wortmannin (phosphatidylinositol $3^{\prime}$-kinase (PI3K) inhibitor) reduced the uptake of apoptotic cells, but the engulfment of necrotic cells remained unaffected. Our data demonstrate that apoptotic and necrotic cells are internalized differently by macrophages.

Cell Death and Differentiation (2006) 13, 2011-2022.

doi:10.1038/sj.cdd.4401900; published online 21 April 2006

Keywords: phagocytosis; macropinocytosis; apoptosis; necrosis; internalization mechanisms

Abbreviations: PS, phosphatidylserine; PI, propidium iodide; FACS, fluorescence activated cell sorter; SEM, scanning electron microscopy; TEM, transmission electron microscope; LY, Lucifer Yellow; HRP, horseradish peroxidase; PI3K, phosphatidylinositol 3'-kinase; mTNF, recombinant murine tumor necrosis factor; antiFas antibodies, agonistic antihuman Fas antibodies; DAPI, 2,6- diamidino-2-fenylindole; DAB, diaminobenzidine; PARP, poly (ADP-ribose) polymerase

\section{Introduction}

Apoptosis is a highly regulated process in which the cell activates an intrinsic suicide mechanism that rapidly leads to cell shrinkage, chromatin condensation, membrane blebbing, and the formation of one or more apoptotic bodies. ${ }^{1}$ Apoptotic cells are cleared rapidly and efficiently as intact cells or apoptotic bodies by professional phagocytes or neighboring cells. A broad array of phagocyte receptors, apoptotic-cellassociated ligands and intermediate molecules has been proposed to mediate phagocytosis of apoptotic cells. These receptors on the phagocyte include integrins (e.g. $\alpha_{v} \beta_{3}$ ), scavenger receptors (e.g. CD36), immunoglobulin superfamily molecules (e.g. CD31) and receptors for complement (e.g. CD91/calreticulin) ${ }^{2-5}$ Additional molecules, such as thrombospondin, Clq, mannose-binding lectin, C-reactive protein and milk fat globule EGF factor 8 may serve as intermediates that bridge macrophage and apoptotic-cell surfaces or act as opsonins. ${ }^{3,5-7}$ The best-studied surface change on apoptotic cells is the externalization of phosphatidylserine (PS) due to loss of plasma membrane phospholipid asymmetry. ${ }^{8}$ Apoptotic cell clearance is characterized by the lack of induction of proinflammatory macrophage responses and can exert anti-inflammatory effects on macrophages as evidenced by their release of soluble anti-inflammatory mediators, such as transforming growth factor $\beta$, prostaglandin E2 and platelet activating factor, in response to apoptotic cells. ${ }^{9}$ Moreover apoptotic cell clearance can trigger tolerogenic responses in the adaptive immune system. ${ }^{10}$ Additional mechanisms may contribute to the anti-inflammatory reaction, for example apoptotic cells themselves can produce immunomodulatory factors such as IL-10 ${ }^{11}$ and TGF- $\beta .^{12}$ Since the persistence of apoptotic cells can have harmful consequences, such as inflammation and autoimmune disease, their efficient removal is of significant biological relevance. In contrast, necrotic cell death typically occurs following exposure to high concentrations of endogenous or exogenous toxins, heat treatment, freeze thawing or other immediately disruptive insults. Leakage of noxious contents from necrotic cells can cause injury to the surrounding tissue and initiates the activation or potentiation of proinflammatory responses. Nevertheless, some reports describe a necrotic-like cell death pathway regulated by an intrinsic death program distinct from that of apoptosis. ${ }^{13,14}$ Unexpectedly, was shown that necrotic cells also externalize $\mathrm{PS}^{15}$ and can be recognized through a PS-dependent mechanism. ${ }^{16,17}$

Two types of internalization processes (endocytosis) have been reported so far. Phagocytosis is the efficient antigen uptake by internalization of large particles, and comprises several separate but usually linked events: attachment, internalization, and digestion of the phagocytosed particles. 
The other process is fluid phase uptake of small molecules, and is performed by two distinct mechanisms: micropinocytosis is the ingestion of small vesicles via clathrin-coated pits, and macropinocytosis is ingestion of fluid via pinosomes formed by membrane ruffling. ${ }^{18}$

It has been proposed that apoptotic cells are taken up by macropinocytosis. ${ }^{5,19}$ The authors suggested that a similar mechanism is used for the uptake of necrotic cells. However, in a previous ultrastructural study it had been suggested that macrophages use different internalization mechanisms, depending on how the target cell has died: phagocytosis for apoptotic cells, and macropinocytosis for necrotic cells. ${ }^{20}$ In the present work, we sought to further validate this working hypothesis by an in vitro phagocytosis assay, using apoptotically or necrotically dying L929sAhFas cells as target cells, and a mouse macrophage cell line (Mf4/4) as professional phagocytes. We observed by scanning electron microscopy (SEM) that macrophages taking up apoptotic or necrotic cells have different surface characteristics. Using two fluid phase markers, Lucifer Yellow (LY) and horseradish peroxidase (HRP), we also demonstrated the existence of different internalization mechanisms: 'zipper'-like phagocytosis for apoptotic cells and macropinocytosis for necrotic cells. Finally, we demonstrated that wortmannin, a phosphatidylinositol $3^{\prime}$-kinase (PI3K) inhibitor, differentially influences the uptake of apoptotic and necrotic cells.

\section{Results}

\section{Description of apoptotic versus necrotic cell death}

L929sAhFas, when stimulated by anti-Fas, die rapidly by apoptosis, but necrotically when exposed to recombinant murine tumor necrosis factor (mTNF). In order to assess apoptotic versus necrotic cell death, several cell death parameters were studied, such as caspase activation, poly(ADP-ribose) polymerase (PARP) cleavage, and PS exposure at the surface and cell membrane permeabilization. Apoptotic cell death is characterized by DEVDase activity and consecutive cleavage of PARP, while in the case of TNFmediated necrotic cell death there is absence of DEVDase activity and PARP proteolysis (Figure $1 \mathrm{a}$ and $\mathrm{b}$ ). PS exposure (Annexin-V-FITC labeling) and loss of membrane integrity (propidium iodide (PI) staining) of target cells was determined by fluorescence activated cell sorter (FACS) assay before using them in the in vitro phagocytosis assay (Figure 1c).

\section{SEM analysis of surface characteristics of macrophages during internalization of apoptotic and necrotic cells}

In order to further characterize the distinct internalization mechanisms used by macrophages to engulf apoptotic and necrotic cells, we used the in vitro phagocytosis assay described by Brouckaert et al. ${ }^{17}$ and studied surface characteristics of macrophages and target cells by SEM. Mouse macrophages (Mf4/4) were used as professional phagocytes, and L929sAhFas cells treated with anti-Fas or mTNF to induce apoptotic or necrotic cell death, respectively, were used as target cells. All coculture experiments were
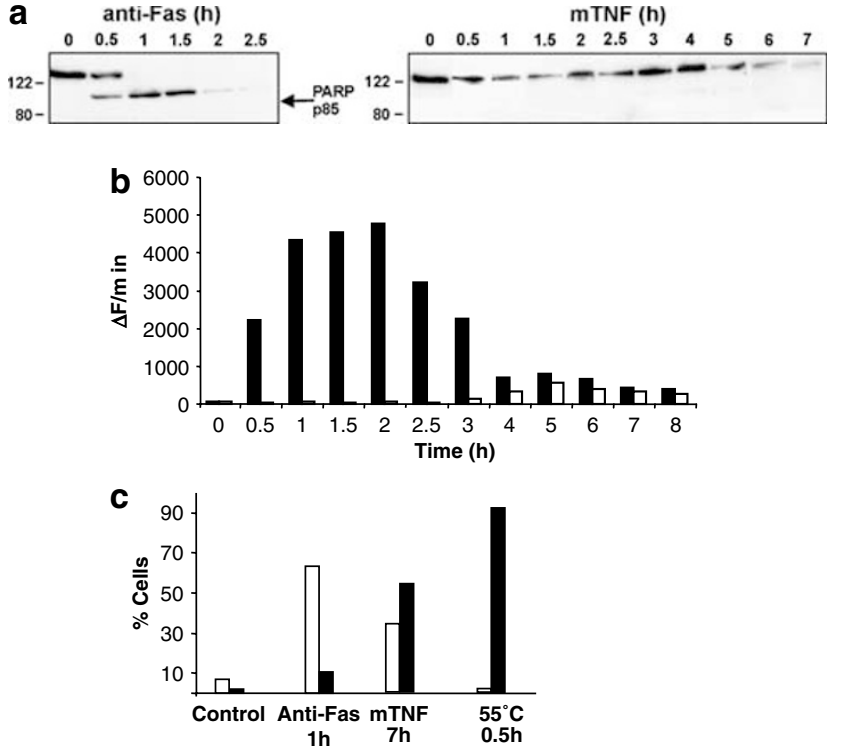

Figure 1 (a) Immunoblots for PARP show the appearance of an $85-\mathrm{kDa}$ cleaved fragment of PARP in apoptosis but not in necrosis. (b) Time kinetics analysis of caspase activity was measured by Ac-DEVD-amc cleavage. Black bars represent apoptotic and white bars necrotic cell death. (c) PS exposure was determined by Annexin V binding and cells were simultaneously stained with PI to assess cell permeability. White bars represent PS positive and PI negative cells and black bars represent PS and PI positive cells for anti-Fas induced apoptosis, mTNF- and heat-induced necrosis

carried out in the presence of heat-inactivated serum, as the presence of heat-inactivated serum in our experimental setup did not significantly affect the phagocytic uptake of apoptotic and necrotic cells, which is in agreement with findings of Hart et al. $^{21}$ (Supplementary Figure 1 is available online at http:// www.nature.com/cdd/index.html).

In control conditions, the spindle-shaped L929sAhFas cells rounded up during the short coculture time and the harvesting process (Figure 2a). Most of the control macrophages were attached, flattened, and spread onto the surface of plates (Figure 2a). Macrophages demonstrated marked variations in size, shape, and degree of spreading. Small ruffles were occasionally observed on the surface of macrophages, but no uptake of healthy control target cells was detected (Figure 2a).

After induction of apoptosis in L929sAhFas cells by treatment with anti-Fas for $1 \mathrm{~h}$ and coculture with macrophages, apoptotic L929sAhFas cells formed rounded surface protuberances characteristic of budding phenomena (Figure 2b), a well-known feature of apoptosis. Sometimes as many as three apoptotic bodies were seen attached to the cell surface or in the process of being internalized by a single phagocyte (Figures 2b and $b^{\prime}$ ). Macrophages internalizing apoptotic bodies displayed narrow pseudopods extending over the surface of apoptotic bodies and enclosing them on all sides (Figures $2 b$ and $b^{\prime}$ ). Spherical or hemispherical craters with rolled edges containing remnants of apoptotic bodies were occasionally observed (Figures $2 c$ and $c^{\prime}$ ). A more prominent feature of macrophages cocultured with apoptotic or necrotic cells, but not frequently seen in macrophages cultured with unstimulated control cells, was the presence of 

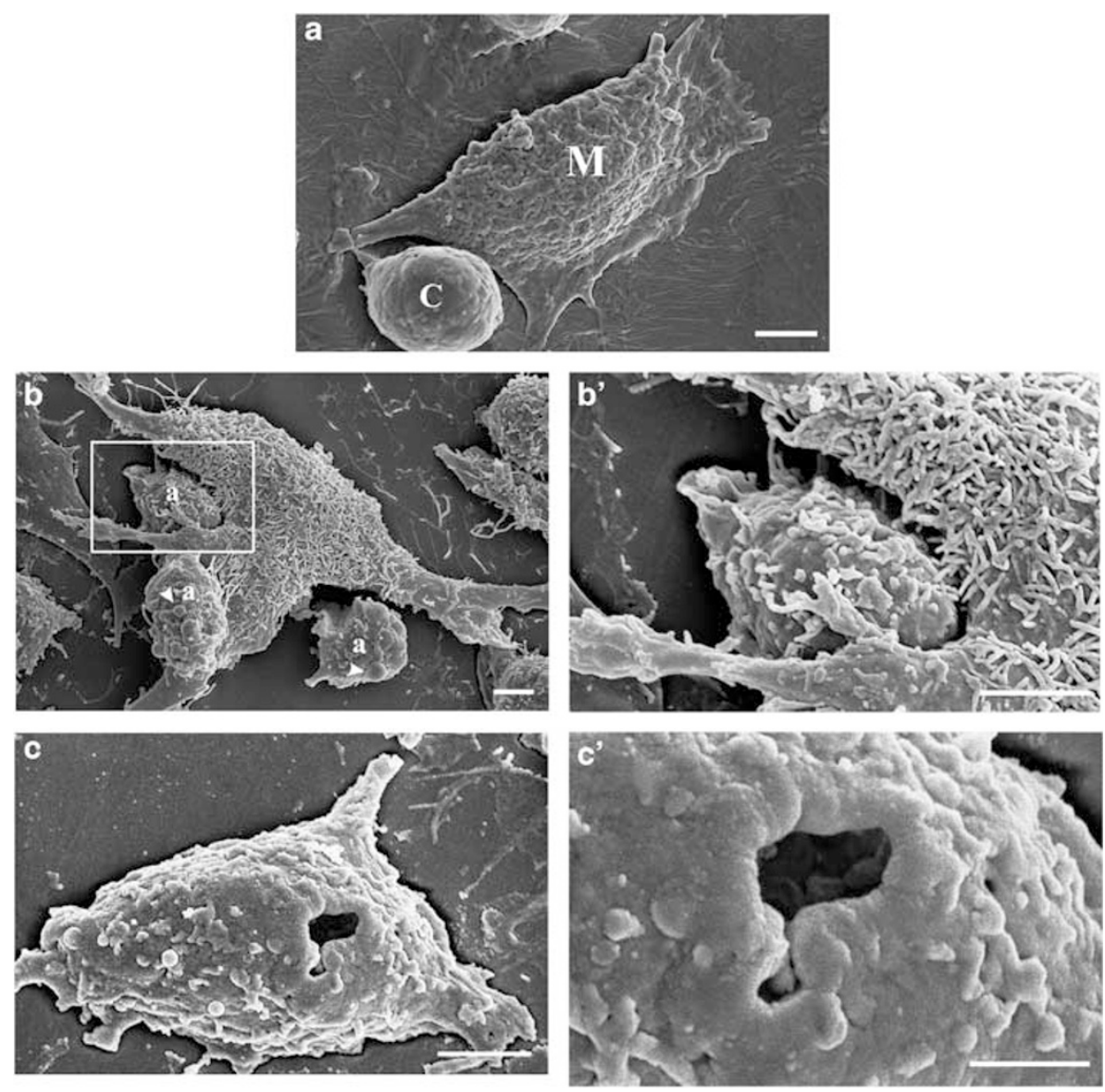

Figure 2 SEM micrographs. (a) Control. Unstimulated L929sAhFas cells (C) were cocultured with Mf4/4 macrophages (M). No uptake of healthy cells or membrane ruffles were observed. Note absence of microvilli on the surface of the macrophage. (b) Overview, process of internalization of apoptotic bodies (a) by a macrophage. Budding of apoptotic cells (arrowheads). ( $\mathbf{b}^{\prime}$ ) Enlargement of rectangle in (b) Formation of pseudopods during the internalization of an apoptotic body. Note numerous microvilli on the surface of the macrophage. (c) Overview, formation of craters on the surface of a macrophage during coculture with apoptotic cells. (c') Detail of (c).

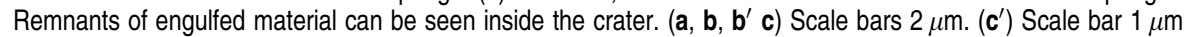

multiple fine cytoplasmic microvilli emanating from the entire cytoplasm of the macrophages (Figures $2 b$ and $b^{\prime}$ ).

TNF-induced necrotic cells had irregular surface changes that were not observed during apoptotic cell death (Figure $\left.3 b^{\prime}\right)$. Macrophages internalizing necrotic material had broad membrane ruffles (Figures $3 a$ and $b$ ) terminating in long fine protrusions (Figures $3 b^{\prime}$ ). Necrotic material can be observed between these protrusions (Figures $3 b^{\prime}$ ). Comparison of SEM pictures with transmission electron microscope (TEM) images suggests that these protrusions, when retracting, take up the necrotic material inside the macrophages. In general, macrophages cocultured with necrotic cells had shapes that were far more varied and irregular than macrophages cocultured with apoptotic cells, and displayed prominent ruffles.

\section{Analysis of internalization mechanisms using fluid phase markers: lucifer yellow and horseradish peroxidase}

In the next part of our work, we used two different fluid phase markers to discriminate between the distinct mechanisms of internalization used by macrophages to engulf apoptotic and necrotic cells. Fluid-phase pinocytosis is usually studied by detecting the cellular accumulation of different soluble and impermeant probes, such as LY and HRP. ${ }^{22-24}$ Intracellular distribution of LY and HRP was followed in cocultures of macrophages and target cells (unstimulated, apoptotic and necrotic): LY with fluorescence microscopy, and HRP with light and transmission electron microscopy. In cocultures with unstimulated living target cells, a few macrophages showed evidence of vacuoles containing LY or HRP, demonstrating that Mf $4 / 4$ were engaged in constitutive macropinocytosis, but no uptake of living control target cells was observed (Figures $5 \mathrm{a}$ and $6 \mathrm{a})$.

When macrophages were cocultured with apoptotically dying cells in the presence of LY or HRP, uptake of apoptotic bodies was not accompanied by uptake of LY or HRP (Figures $4 a, b, 5 b, 6 b$ and $c$ ). Although both by SEM (Figures 2 ) and TEM we observed regularly the attachment of several apoptotic bodies to one macrophage, we never found internalization of more than one apoptotic body per macrophage (Figures $5 b$ and $6 b$ ). In contrast, when primary (TNFinduced necrotic) (Figures 4c, 5c, 6d and e) or secondary 

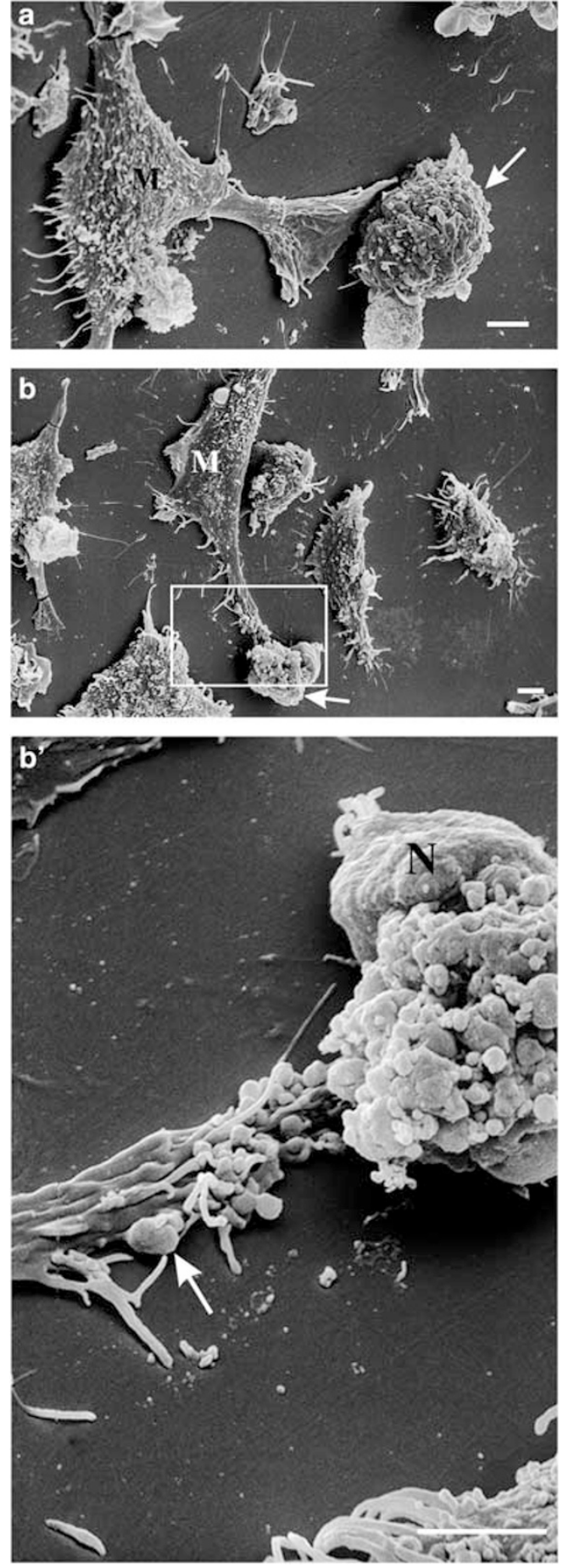

Figure 3 SEM micrographs of TNF-induced necrotic cell internalization. (a) Macrophage (M) demonstrating broad ruffling towards the necrotic cell (arrow). (b) Clearance of necrotic material (arrow). Macrophage (M) displays flat membrane ruffle directed towards the necrotic debris. ( $\left.\mathbf{b}^{\prime}\right)$ Detail of the rectangle in (b). Necrotic material (arrow) seems to be grasped by tiny protrusions emanating from the membrane ruffle of the macrophage. Note that the necrotic cell (N) has an irregular surface. Scale bars $2 \mu \mathrm{m}$

necrotic cells (Figures $4 \mathrm{a}$ and b) were taken up by the macrophages, both fluid phase tracers were colocalized with engulfed necrotic material. At the ultrastructural level, macro- pinosomes were initially irregular in size and shape, contained both HRP and necrotic material, and assumed a rounder appearance when they were localized more centrally in the cell. HRP-labeled areas were often seen at the cell periphery, near lamellar membrane projections corresponding to ruffling zones, and in cytoplasmic regions that were essentially devoid of other organelles. The reaction product of HRP was never seen attached to the surface of the macrophages or to the necrotic cells (Figure 6d). Similarly, when macrophages were cocultured with necrotic cells, which were killed by heat shock, engulfed necrotic material was colocalized with LY (Figure 4d). In contrast to TNF-induced necrosis, heatinduced necrotic cells were often unfragmented and were taken up as large entities (Figure 6f). However, in this case the macrophage membrane forms numerous ruffles at the interface with the necrotic corpses with formation underneath of spacious macropinosomes with coingestion of necrotic material and HRP (Figure 6g).

\section{Analysis of internalization mechanisms using the PI3K inhibitor wortmannin}

$\mathrm{PI} 3 \mathrm{~K}$ are activated during phagocytosis induced by several receptors, and studies using inhibitors such as wortmannin showed that it is required for phagocytosis of apoptotic cells. ${ }^{25,26}$ However, the requirement for $\mathrm{PI} 3 \mathrm{~K}$ in phagocytosis of necrotic cells has not been tested. To investigate whether the uptake of apoptotic and necrotic cells by macrophages is PI3K dependent, macrophages were pretreated for $30 \mathrm{~min}$ with increasing doses of wortmannin (10-100 nm range) and percent of uptake was evaluated by FACS analysis. These results showed that wortmannin decreased the percent of uptake of apoptotic cells by the macrophages in a dosedependent manner, but did not affect the uptake of necrotic cells (Figure 7).

\section{Discussion}

Insights into the morphological features of the process of clearing dead cells have been largely based upon the twodimensional views furnished by light and TEM, ${ }^{20,27-30}$ but relatively little is known concerning the surface topography of interaction of macrophages with dying target cells. In the present study, we used SEM to visualize in 3-D the differences in the surface properties of macrophages ingesting either apoptotic or necrotic L929sAhFas cells. Apoptotic cells that underwent budding (Figure $2 \mathrm{~b}$ ) were swiftly internalized by phagocytosis as well-enclosed distinct apoptotic bodies (Figures $2 b$ and $b^{\prime}$ ). SEM examination showed that during phagocytosis of apoptotic bodies the phagocytic plasma membrane envelopes the apoptotic bodies as a closely fitting sleeve (Figure $2 b^{\prime}$ ), which is similar to the zipper model of phagocytosis proposed by Griffin et al. ${ }^{31,32}$ According to the zipper model of phagocytosis, pseudopod advance over a particle is guided by interactions of cell surface receptors, and so the phagosomal membrane should be closely apposed to the particle surface. ${ }^{33}$ The integrity of the apoptotic body's plasma membrane is an important requirement for this mechanism. These data are in agreement with the 

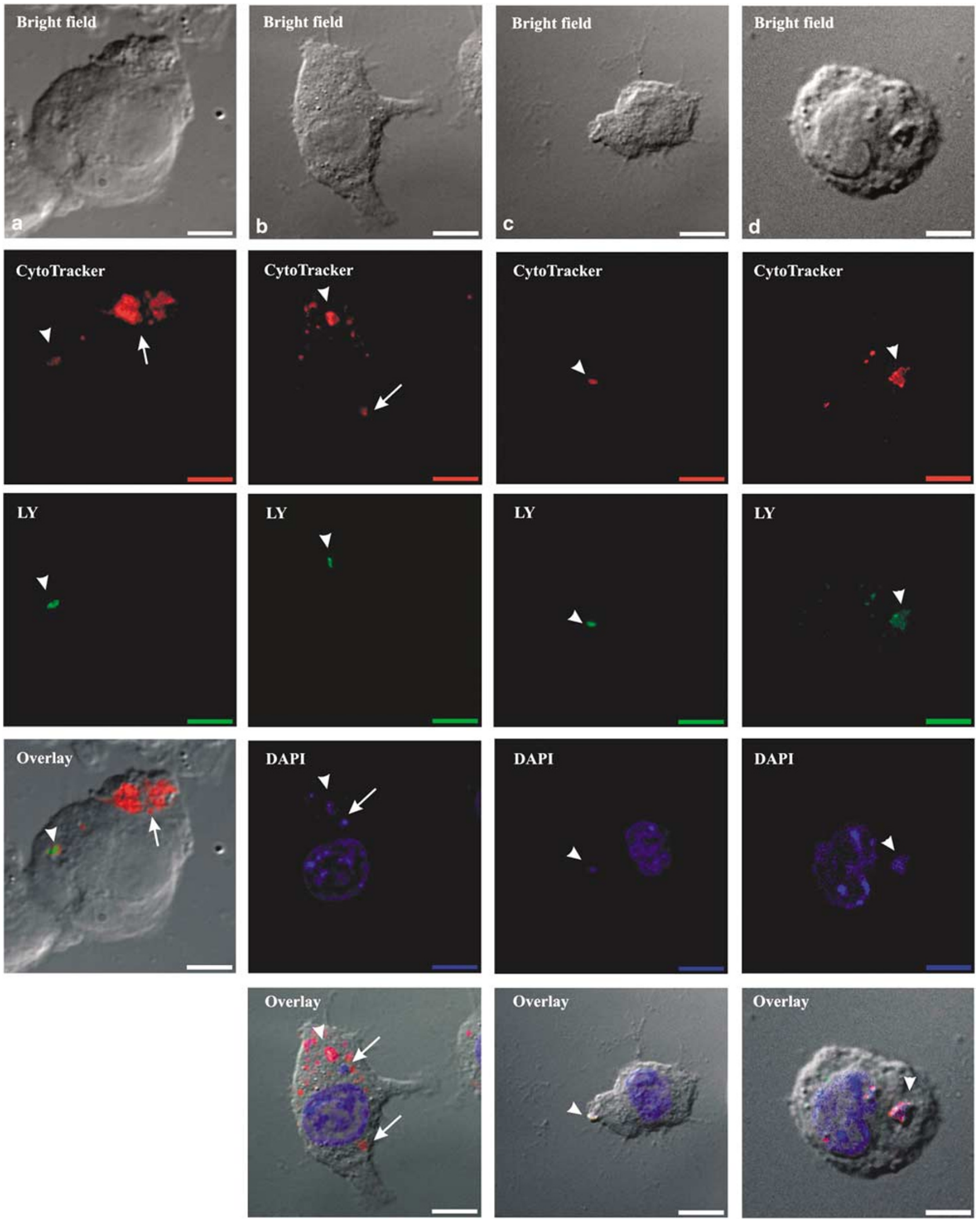

Figure 4 Fluorescence microscopy. Coculture of macrophages with apoptotic (a and b), TNF- (c) and heat-induced necrotic (d) cells in the presence of LY. Target cells were pre-stained with Cytotracker Red (Cytotracker). Uptake of apoptotic cytoplasmic and nuclear (DAPI stained) material by the macrophages without coingestion of $L Y$ (arrows in $\mathbf{a}$ and $\mathbf{b}$ ) while secondary necrotic material is engulfed with coingestion of LY (arrowheads in $\mathbf{a}$ and $\mathbf{b}$ ). Ingestion of TNF- (c) and heat-induced (d) necrotic material by the macrophages was accompanied by uptake of LY (arrowheads in $\mathbf{c}$ and $\mathbf{d}$ ), which colocalized in the same macropinosomes. Scale bars $8 \mu \mathrm{m}$ 

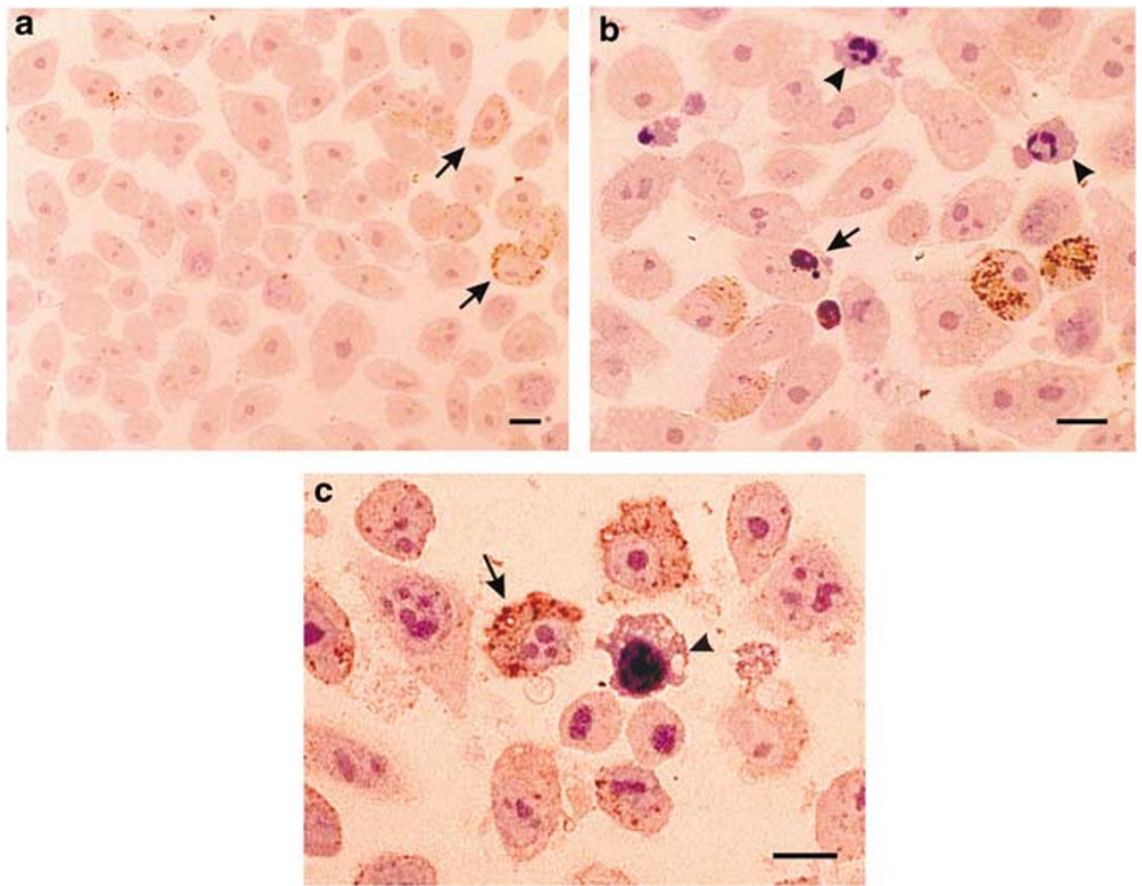

Figure 5 Light microscopy. (a) Coculture of macrophages with unstimulated L929sAhFas cells in the presence of HRP (control). Note the presence of HRP positive vacuoles of uniform dimension in the macrophages (arrows). (b) Coculture of macrophages with apoptotic target cells in the presence of HRP. Notice apoptotic cells with marginated condensed chromatin (arrowheads). Internalized apoptotic body and phagosome devoid of HRP (arrow). (c) Coculture of macrophages and TNF-induced necrotic cells in the presence of HRP. Macrophage in the vicinity of necrotic cell (arrowhead) contains several HRP positive vacuoles of variable dimension (arrow). Note a necrotic cell (arrowhead). Scale bars $10 \mu \mathrm{m}$

observations of Giles et al., ${ }^{34}$ who used SEM to demonstrate a zipper-like interaction between a human monocyte-derived macrophage and an apoptotic neutrophil. In addition, in the present study craters were occasionally observed on the surface of macrophages cocultured with apoptotic cells (Figures 2c and $c^{\prime}$ ). A mechanism of 'sinking-in craters' for internalization of apoptotic cells in early embryogenesis of the chick lens rudiment has been documented by Garcia-Porrero et al. $^{35}$ This mechanism can be considered as a variation of the zipper model. ${ }^{33}$ L929sAhFas cells treated with mTNF underwent necrosis; SEM showed that their surfaces were irregular, pointing to loss of the integrity of the plasma membrane (Figure 3). Macrophages attempting to engulf necrotic cells demonstrated numerous broad membrane ruffles that ended in long fine protrusions creeping up necrotic material (Figure $3 b^{\prime}$ ). It was recently proposed that formation of the ruffles is a specific feature of macropinocytosis. ${ }^{36}$ Our SEM data revealed distinct surface features of macrophages: apoptotic target cells induce narrow pseudopods, whereas necrotic target cells induce broad membrane ruffles that are disproportional to the engulfed necrotic material.

The microvilli present at the surface of the macrophage disappear upon completion of the internalization process as can be seen when comparing Figure $2 b$ with $c$. Indeed on Figure $2 c$ the macrophage is already finalizing the process of engulfment while on Figure $2 \mathrm{~b}$ apoptotic bodies are still attaching to the surface of the macrophage and are in the process of engulfment. It has been shown that macrophages may possess a membrane reserve in their microvilli, which can be utilized for spreading and initiating cell locomotion. ${ }^{37,38}$
In addition, Dini et al. $^{39}$ showed that reduction in microvilli is paralleled by the progressive decrease of binding and uptake capacity of Kupffer cells. Another explanation may be that these microvilli facilitate recognition of the apoptotic cells and participate in attachment of apoptotic bodies to the surface of the macrophage during the internalization process. In that context, it has been shown that microvilli express different receptors such as the selectins, ${ }^{40}$ the integrins $\alpha 4 \beta 7$ and $\alpha 4 \beta 11^{41,42}$

A second approach in the present study consisted of using the fluid phase markers $L Y$ and HRP as tracers, adding functional data in support of the SEM. A critical requirement for any marker solute is that it can be taken up in the fluid phase, without adsorption to the cell surface. Cytochemically, the HRP reaction product was never seen attached to the surface of the macrophages or the necrotic cells, thereby excluding the possibility of nonspecific entrapment of HRP by the necrotic cells (Figure 6d). This observation is in line with the findings of Steinman and Cohn. ${ }^{22}$ These authors could not detect HRP attached to the surface of macrophages, but in cells exposed to the enzyme for just 5-10 min it was easily observed in intracellular vesicles. These features of HRP uptake constitute an additional argument for an uptake in the fluid phase that is clearly different from uptake of materials that bind to the cell surface before engulfment. When LY and HRP were added to cocultures of apoptotic cells and macrophages, apoptotic bodies inside the macrophages formed tightly enclosed phagosomes devoid of the $L Y$ and HRP reaction products (Figures $4 a, b, 5 b, 6 b$ and $c$ ). In contrast, during internalization of TNF-induced necrotic and 

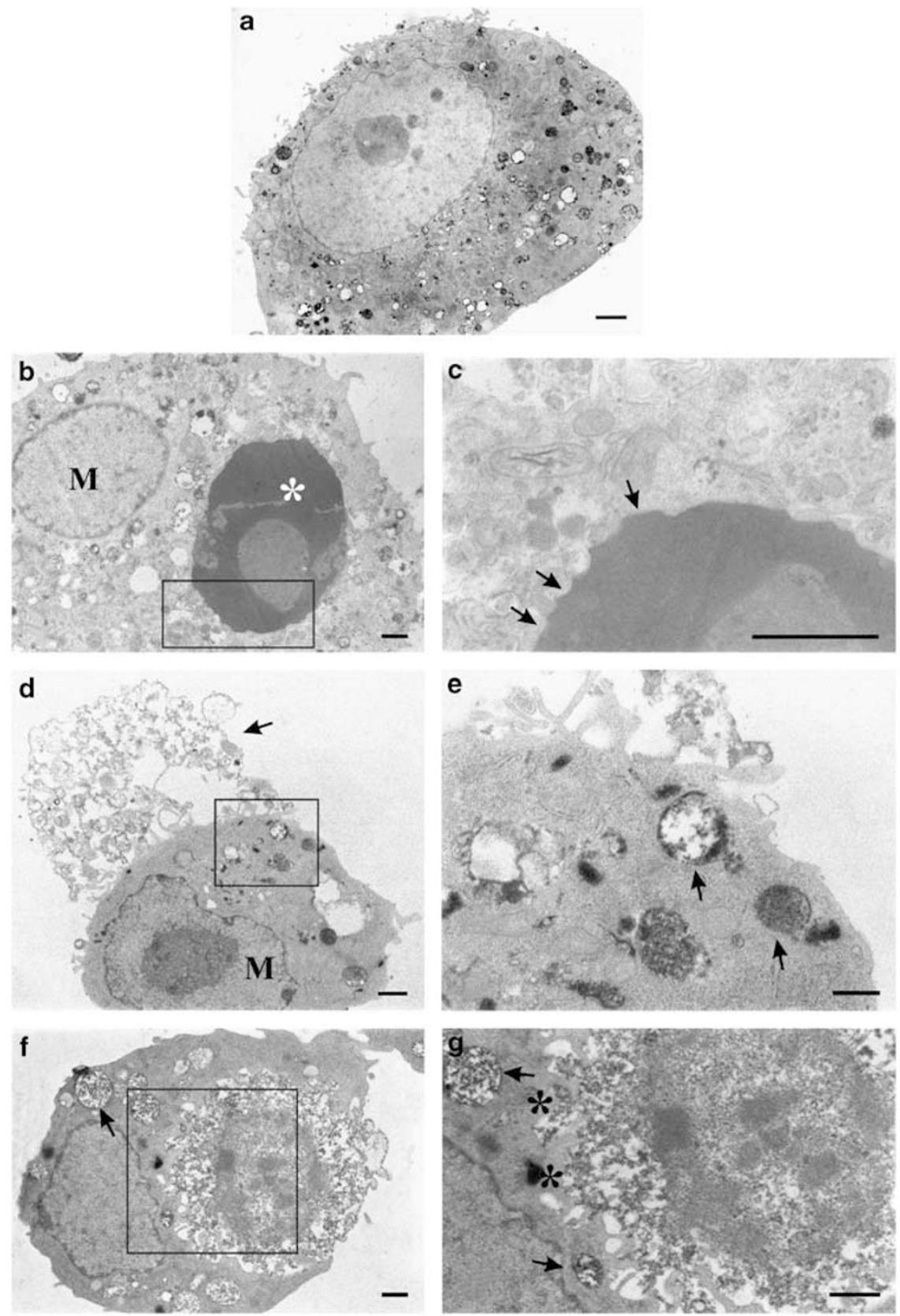

Figure 6 Transmission electron micrographs. (a) Macrophages cocultured with unstimulated L929sAhFas cells in the presence of HRP (control). Note HRP positive vacuoles in the macrophages as a signature of constitutive endocytosis. (b) Coculture of macrophages and apoptotic cells in the presence of HRP. The phagosome of the macrophage (M) is devoid of HRP and contains an engulfed apoptotic body (asterisk). (c) Detail of rectangle in (b). An apoptotic body internalized by a macrophage demonstrating the absence of HRP and formation of a tightly fitting phagosome. Note a double membrane structure (arrows) formed by the phagosomal and apoptotic body membranes. (d, e) Macrophages cocultured with TNF-induced necrotic cells in the presence of HRP. (d) Note absence of the HRP reaction products at the surface of the macrophage (M) and remnants of the necrotic cell (arrow). (e) Detail of rectangle in (d). Colocalization of HRP and necrotic material in the macropinosomes (arrows). Note that necrotic material is located in the spacious macropinosomes. (f, $\mathbf{g})$ Macrophages cocultured with heat-induced necrotic cells in the presence of HRP. (f) Nearly complete encircling by the macrophage of a necrotic cell corpse. (g) Detail of rectangle in (f). Note formation of ruffles at the surface of the macrophage (asterisks) with underneath the creation of spacious macropinosomes with coingestion of HRP and necrotic material (arrows). Scale bars $1 \mu \mathrm{m}$

secondary necrotic material, numerous LY and HRP positive macropinosomes containing engulfed necrotic material were observed inside the macrophages (Figures 4c, 5c, 6d and e). Although cells killed by heat shock, producing unfragmented cells, were internalized as big entities, we never observed the formation of tightly fitting phagosomes as in the case during the uptake of apoptotic bodies (Figures $6 f$ and $g$ versus $6 \mathrm{~b}$ and c). In contrast, macrophages displayed numerous ruffles at the contact site with heat-induced necrotic cells, with the formation of macropinosomes containing both HRP reaction product and necrotic debris at the base of the ruffles (Figure $6 \mathrm{~g}$ ). As was the case for clearance of TNF-induced 


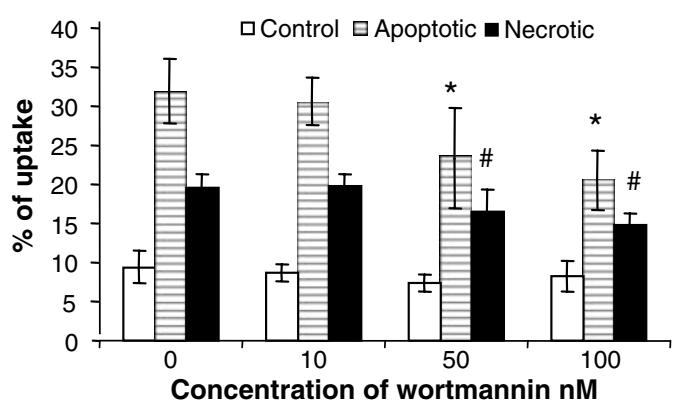

Figure 7 Macrophages were pretreated for $30 \mathrm{~min}$ with the indicated doses of wortmannin and cocultured with control (unstimulated), apoptotic or TNF-induced necrotic cells. A two-parameter flow cytometry phagocytosis assay was used to quantify the percentage of uptake as described in 'Materials and Methods.' Wortmannin decreased the percentage of uptake of apoptotic cells in a dose dependent manner but had no effect on the uptake of necrotic cells. Significantly different ${ }^{*}$ ) and not significantly different (\#) from condition without wortmannin $(0 \mathrm{nM}), P<0.001$ (Banferroni's multiple comparison test). Error bars represent the SD of at least three independent experiments, each one performed in duplicate

necrotic cells, heat-induced necrotic material was colocalized with LY (Figure 4d). In addition, in order to address the controversial issue of cell specificity, we have used in our in vitro phagocytosis assay another cell type as target cell. For this purpose, we applied a well-characterized model system for apoptotic or necrotic cell death, Jurkat E cells stimulated with anti-Fas or FADD-deficient Jurkat cells stimulated with hTNF $^{43,44}$ (Supplementary materials and methods are available online at http://www.nature.com/cdd/index.html). We could confirm the data obtained for L929sAhFas cells, namely that the fluid phase marker HRP was coingested in the same macropinosomes with necrotic material, revealing a macropinocytotic mechanism of internalization, while tracer was absent in the phagosomes containing apoptotic bodies, pointing to the zipper-like mechanism of internalization (Supplementary Figure 2 is available online at http://www. nature.com/cdd/index.html). All these findings contrast with the results of Hoffmann et al. ${ }^{19}$ and Ogden et al. ${ }^{5}$ These authors demonstrated by fluorescence microscopy that uptake of apoptotic cells initially involves formation of spacious phagosomes with coingestion of LY, implying a macropinocytotic mechanism for the internalization of apoptotic cellular material. ${ }^{5,19}$ This discrepancy might reflect the use of different triggers to induce death in target cells (Fasmediated apoptosis in the present study versus UV irradiation in Hoffmann et al. ${ }^{19}$ and Ogden et al. ${ }^{5}$ ), which can determine the extent to which cells are recognized and removed by phagocytes. ${ }^{45}$ Another more likely explanation for these opposing data might be the use of late apoptotic cells in the study of Ogden et al. (2001), which display the morphological features of secondary necrosis. An additional argument suggesting that Ogden et al. ${ }^{5}$ used late apoptotic cells is their provision of evidence that $\mathrm{C} 1 \mathrm{q}$ and mannose-binding lectin (MBL), a member of the collectin family of proteins, bind to apoptotic cells and stimulate ingestion by the macrophages. It has been shown that $\mathrm{C} 1 \mathrm{q}$ and $\mathrm{MBL}$ bind to apoptotic cells rather late in the cell death process; C1q binding to early apoptotic cells is much weaker than to late apoptotic cells, and binding of $\mathrm{MBL}$ was demonstrated exclusively on late apoptotic cells. ${ }^{46,47}$

In addition, Brouckaert et al. ${ }^{17}$ showed in the same model system as used in the present study that uptake of necrotic cells is quantitatively and kinetically less efficient than the uptake of apoptotic cells, and so uptake by macropinocytosis seems to be inefficient compared to zipper-like phagocytosis. As Cocco and Ucker ${ }^{48}$ reported that the macrophage cell line J774A.1 engulfs necrotic cells to the same extent as apoptotic cells, there is a clear need to study the phagocytosis issue in an in vivo model system.

Next, we tested whether uptake of apoptotic and necrotic cells can be differentially affected by wortmannin, a potent fungal toxin that is a specific potent inhibitor of PI3K. It was reported that nanomolar concentrations of wortmannin do not inhibit the activities of any other known protein or lipid kinase. ${ }^{49}$ We found that wortmannin inhibits the uptake of apoptotic cells by macrophages in a dose dependent manner, but has no effect on the uptake of necrotic cells (Figure 7). Remarkably, the extent of engulfment of apoptotic cells was never less than that of necrotic cells, which implies that one of two engulfment mechanisms for removal of apoptotic material might come into play, depending on the stage of apoptosis, only one of which can be blocked by wortmannin. These results suggest that different biochemical processes are associated with the two ultrastructurally different ways of internalizing dead cells, and that PI3K might preferentially participate in clearance of apoptotic cells. Our results are in agreement with the findings of Leverrier and Ridley, ${ }^{25}$ and $\mathrm{Hu}$ et al., ${ }^{26}$ who showed that blocking $\mathrm{PI} 3 \mathrm{~K}$ in macrophages inhibits uptake of apoptotic cells. Moreover, Schpetner et al. ${ }^{49}$ showed that wortmannin did not block the uptake of the soluble phase marker LY, which is taken up by the macropinocytotic mechanism. Their data correlate with our finding that wortmannin had no effect on the uptake of necrotic cells, which were internalized by macropinocytosis with coingestion of the fluid phase markers LY and HRP.

If different internalization mechanisms exist, then a question arises about the biological relevance of the mechanisms used by macrophages for the uptake of apoptotic and necrotic cells. It has been shown that the mechanism of antigen uptake is decisive in determining the type of immunological responses to the antigens. ${ }^{50}$ In addition, antigen presentation by macrophages was enhanced by the uptake of necrotic but not apoptotic cells. ${ }^{51}$ In this regard, the zipper-like mechanism of phagocytosis of apoptotic cells is precise and selective, which is in agreement with indications that apoptotic cell removal is immunologically silent. In contrast, necrotic material is coingested with extracellular fluid present in the vicinity of the budding macropinosomes. The mechanisms of uptake might thus contribute to the difference in immune responses consequent to exposure to and uptake of apoptotic and necrotic cells.

The data presented here demonstrate that macrophages use different mechanisms to internalize apoptotic and necrotic cells: zipper-like phagocytosis for apoptotic cells and macropinocytosis for necrotic cells (the main features are summarized in Table 1). The challenge ahead is to understand the basic cellular machineries required for internalizing apoptotic and necrotic cells. This understanding might generate useful 
Table 1 Comparative characteristics of the mechanisms of apoptotic and necrotic L929sAhFas cell uptake by the Mf4/4, a macrophage cell line

\begin{tabular}{|c|c|c|}
\hline & $\begin{array}{l}\text { Apoptotic cells uptake } \\
\text { (zipper-like mechanism) }\end{array}$ & $\begin{array}{l}\text { Primary and secondary necrotic material } \\
\text { uptake (macropinocytotic mechanism) }\end{array}$ \\
\hline $\begin{array}{l}\text { Structure inside the } \mathrm{Mf}^{\mathrm{C}} \\
\text { Proportionality of } \mathrm{Mf} \text { extensions versus } \\
\text { particle size }\end{array}$ & $\begin{array}{l}\text { Tight-fitting phagosomes } \\
\text { Proportional }\end{array}$ & $\begin{array}{l}\text { Spacious macropinosomes } \\
\text { Disproportional }\end{array}$ \\
\hline $\begin{array}{l}\text { Integrity of plasma membrane }{ }^{\mathrm{a}, \mathrm{c}, \mathrm{b}} \\
\text { Efficiency } \\
\text { PS dependency } \\
\text { Coingestion of extracellular fluid and } \\
\text { fluid phase markers (HRP and LY) }\end{array}$ & $\begin{array}{l}\text { Required } \\
\text { Efficient } \\
\text { Dependent } \\
\text { No }\end{array}$ & $\begin{array}{l}\text { Not required } \\
\text { Inefficient } \\
\text { Dependent } \\
\text { Yes }\end{array}$ \\
\hline $\mathrm{PI} \mathrm{K}^{\mathrm{a}}$ & Dependent & Independent \\
\hline
\end{tabular}

Both PS dependency and effect of PI3K was tested for apoptotic and TNF-induced necrotic cells but not for heat-induced necrotic cells. The data are summarized from the present ${ }^{\mathrm{a}}$ and previous reports ( ${ }^{\mathrm{b}}$ Brouckaert et al. ${ }^{22}$; ${ }^{\mathrm{C}}$ Krysko et al. ${ }^{27}$ )

clues for unraveling the underlying control processes involved, and provide the basis for novel strategies to manipulate clearance of apoptotic and necrotic cells for therapeutic purposes.

\section{Materials and Methods}

\section{Cells}

The mouse fibrosarcoma cell line L929sA was selected for its sensitivity to the cytotoxic activity of TNF. ${ }^{52}$ L929sA were stably transfected with the human Fas receptor to produce L929sAhFas cells, as described previously. ${ }^{52}$ L929sAhFas cells were grown in DMEM medium supplemented with $10 \%$ fetal calf serum (FCS), penicillin $(100 \mathrm{U} / \mathrm{ml})$, streptomycin $(0.1 \mathrm{mg} / \mathrm{ml})$ and glutamax I $(200 \mu \mathrm{M})$.

Mf4/4, a mouse macrophage cell line characterized by Desmedt et al., ${ }^{53}$ was grown in RPMI medium (Gibco/BRL, Eggenstein, Germany) supplemented with $10 \%$ FCS, penicillin $(100 \mathrm{U} / \mathrm{ml})$, streptomycin $(0.1 \mathrm{mg} /$ $\mathrm{ml})$, glutamax I $(200 \mu \mathrm{M}), \beta$-mercaptoethanol $\left(2 \times 10^{-5} \mathrm{mM}\right)$, and sodium pyruvate $(1 \mathrm{mM})$, and kept in LPS-free conditions.

\section{Antibodies, cytokines and reagents}

mTNF was produced in Escherichia coli and purified to at least $99 \%$ homogeneity and specific activity of $6 \times 10^{7} \mathrm{IU} / \mathrm{ml}$ as determined in a standardized cytotoxicity assay using L929sA cells (Department for Molecular Biomedical Research, VIB-Ghent University, Ghent, Belgium). Anti-Fas antibodies (anti-Fas, $\lg G_{3}$, clone 2R2) were purchased from BioCheck GmbH (Münster, Germany). AnnexinV-FITC conjugate (BD Pharmingen, San Diego, CA, USA) was used at $1 \mu \mathrm{g} / \mathrm{ml}$. Cell Tracker Green and Orange were from Molecular Probes (Eugene, Oregon, USA), and were used at 0.8 and $10 \mu \mathrm{M}$, respectively. Propidium iodide (BD Biosciences, San Jose CA, USA) was used at $30 \mu \mathrm{M}$.

\section{Induction of apoptotic and necrotic cell death}

L929sAhFas target cells were seeded at $2.5 \times 10^{5}$ cells per well in uncoated 24-well tissue culture plates (Sarstedt, Newton, NC, USA). The next day, for in vitro phagocytosis assay anti-Fas antibody $(250 \mathrm{ng} / \mathrm{ml})$ was added for $1 \mathrm{~h}$ or $\mathrm{mTNF}(10000 \mathrm{lU} / \mathrm{ml})$ for $7 \mathrm{~h}$ L929sAhFas cells were killed by heat shock incubating at $55^{\circ} \mathrm{C}$ for $30 \mathrm{~min} .{ }^{54}$ The cells were harvested at the indicated times and kept on ice until analysis with a FACSCalibur flow cytometer (BD Biosciences). Loss of cell membrane integrity as a measure of cell death was determined by PI fluorescence (ex 535/em 617). PS exposure was monitored by AnnexinV-fluorescein isothiocyanate (FITC) staining (ex 494/em 518).

\section{Caspase enzymatic activity}

The fluorogenic substrate assay for caspase activity was carried out as described previously. ${ }^{55}$ Briefly, $2.5 \times 10^{5}$ cells $/ \mathrm{ml}$ were treated with TNF or anti-Fas. Then cells were washed in cold phosphate buffer and lysed in $75 \mu \mathrm{l}$ of caspase lysis buffer (supplemented with glutathione at a final concentration of $1 \mathrm{mM}$ ). Cell debris was removed by centrifugation and caspase activity was determined by incubating $25 \mu$ of the soluble fraction with $50 \mu \mathrm{M}$ of Ac-DEVD-amc in $150 \mu$ l of cell-free system buffer, containing $220 \mathrm{mM}$ mannitol, $68 \mathrm{mM}$ sucrose, $2 \mathrm{mM} \mathrm{MgCl} 2,2 \mathrm{mM} \mathrm{NaCl}$, $2.5 \mathrm{mM} \mathrm{KH}_{2} \mathrm{PO}_{4}, 0.5 \mathrm{mM}$ EDTA, $0.5 \mathrm{mM}$ sodium pyruvate, $0.5 \mathrm{mM}$ L-glutamine, $10 \mathrm{mM}$ HEPES-NaOH pH 7.4 and $10 \mathrm{mM}$ dithiothreitol. The release of fluorescent 7-amino-4-methylcoumarin was measured for $60 \mathrm{~min}$ at 2-min intervals by fluorometery (excitation at $360 \mathrm{~nm}$ and emission at $480 \mathrm{~nm}$ ) (Cytofluor; PerSeptive Biosystems, Cambridge, MA, USA); the maximal rate of increase in fluorescence was calculated $(\triangle F / \min )$.

\section{Western blot analysis}

Protein extracts from cell lines were prepared by lysis in Laemmli buffer, separated in $12.5 \%$ SDS-PAGE gels, and transferred to nitrocellulose. Antibodies (monoclonal antibody) against PARP and anti-murine HRP as a secondary antibody (BIOMOL Research Laboratories Inc. Technology) were used to probe the blots. Immunoreactive proteins were visualized using chemiluminescence and signals were captured by exposure to film (Amersham Biosciences).

\section{In vitro phagocytosis assay}

In order to quantify uptake of apoptotic and necrotic cells by macrophages, we used a previously described ${ }^{17}$ two-parameter flow cytometry phagocytosis assay, in which apoptotic, necrotic, and viable control L929sAhFas target cells labeled with Cell Tracker Green (Molecular Probes) were incubated with a monolayer of Mf4/4 macrophages labeled with Cell Tracker Orange (Molecular probes). Target cells were stained with $0.8 \mu \mathrm{M}$ Cell Tracker Green (ex 492/em 516), and seeded at $2.5 \times 10^{5}$ cells per well in uncoated 24-well suspension tissue culture plates. Macrophages were stained with $10 \mu \mathrm{M}$ Cell Tracker Orange (ex 540/em 566 ), and seeded in adherent 24-well plates at $2.5 \times 10^{5}$ cells per well. Both target cell and macrophage cultures were incubated overnight at 
$37^{\circ} \mathrm{C}$ in $5 \% \mathrm{CO}_{2}$. At the indicated time points, target cells were induced to undergo apoptosis or necrosis, washed once, and added for coincubation with macrophages resulting in a $1: 1$ ratio of macrophages to target cells (apoptotic and TNF-induced necrotic) and $1: 3$ ratio of macrophages to heat-killed L929sAhFas cells. The cocultures were done in medium containing heat-inactivated serum at $37^{\circ} \mathrm{C}$ in $5 \% \mathrm{CO}_{2}$ for $2 \mathrm{~h}$, after which the cells were detached from the plate with Enzyme Free Cell Dissociation Buffer (Gibco BRL), washed, and resuspended in ice-cold PBS. Data was obtained on a FACScalibur flow cytometer, using Cell Quest software (Becton Dickinson, San Jose, CA, USA). In all, 3000 cells were analyzed at each time point. Control experiments in previous studies revealed that there is no effect of stimulus, MTNF or anti-Fas antibodies, with the protocol used. ${ }^{17}$ The percentage of double-stained macrophages out of the whole macrophage population measures the fraction of the macrophage population involved in phagocytosis of target cells (\% phagocytosis).

\section{Scanning electron microscopy analysis of surface characteristics of macrophages during internalization of apoptotic and necrotic cells}

Adherent cocultures of macrophages and target cells (prepared as described above) were fixed by immersion for $1 \mathrm{~h}$ in prewarmed $\left(37^{\circ} \mathrm{C}\right)$ $2 \%$ glutaraldehyde containing $0.1 \mathrm{M}$ sucrose buffered with $0.1 \mathrm{M}$ Na-cacodylate ( $\mathrm{pH} 7.2$ ). Following several rinses in $0.15 \mathrm{M} \mathrm{Na}$-cacodylate $\mathrm{HCl}$ buffer, cocultures were postfixed for $90 \mathrm{~min}$ in $1 \% \mathrm{OsO}_{4}$ in the same buffer at room temperature and dehydrated in a graded series of ethanol (70, 85, 95 and 100\%; 10 min each). Samples were viewed on a Jeol JSM840 SEM. For quantitative control, FACS assay was performed as described above.

\section{Analysis of internalization mechanisms using Lucifer Yellow}

Lucifer Yellow $\mathrm{CH}$, lithium salt (Molecular Probes, $1 \mathrm{mg} / \mathrm{ml}$ ) was added for $2 \mathrm{~h}$ at $37^{\circ} \mathrm{C}$ to the nonlabeled adherent cocultures of macrophages and target cells labeled with Cell Tracker Orange $(10 \mu \mathrm{M})$ (prepared as described above). Following several extensive rinses in PBS buffer, adherent cocultures were fixed in $3.8 \%$ paraformaldehyde before mounting using Vectashield Mounting medium for fluorescence with DAPI $\mathrm{H}-1200$ (Vector Burlingame) on coverslips. DIC and fluorescence images were obtained at $37^{\circ} \mathrm{C}$ using a Leica DM IRE2 inverted microscope equipped with a HCX PLAPO 63x/1.30 glycerin corrected $37^{\circ} \mathrm{C}$ lens and a cool snap HQ camera. The camera is controlled by the Leica ASMDW acquisition software. Lucifer yellow was measured using a standard GFP filter set, and cell tracker red and DAPI were measured using a combined $B / G / R$ filter set. In order to get $3 D$ information, images were taken at different $z$-levels. Blind de-convolution (MLE-algorithm) and 3D rotations were carried out using the Leica Deblur software. As primary and secondary necrotic cells had showed background staining, we quantified LY fluorescence of primary and secondary necrotic cells by determining the average fluorescence intensity, and then all images were corrected for background staining using the Metamorph 5.0 software.

\section{Ultrastructural analysis of internalization mechanisms using horseradish peroxidase}

$\operatorname{HRP}(1 \mathrm{mg} / \mathrm{ml})$ was added for $2 \mathrm{~h}$ at $37^{\circ} \mathrm{C}$ to the nonlabeled adherent cocultures of macrophages and target cells (prepared as described above). Following several rinses in PBS buffer, adherent cocultures of macrophages and target cells were fixed, on ice, by immersion in $2 \%$ glutaraldehyde containing $1 \mathrm{mM} \mathrm{CaCl}$ and $0.1 \mathrm{M}$ sucrose buffered with $0.1 \mathrm{M} \mathrm{Na}$-cacodylate $(\mathrm{pH} \mathrm{7.4)}$ for $1 \mathrm{~h}$. The fixative was removed with several washes in $0.1 \mathrm{M} \mathrm{Na}$-cacodylate buffer $(\mathrm{pH} 7.4)$, and the presence of $\mathrm{HRP}$ was revealed by incubation of cocultures at $37^{\circ} \mathrm{C}$ in Tris-buffer $(\mathrm{pH}$ 7.6) containing $0.05 \mathrm{M} \mathrm{DAB}$ and $0.1 \% \mathrm{H}_{2} \mathrm{O}_{2}$. Aminotriazole was added to block endogenous catalase activity. After $1 \mathrm{~h}$ the reaction was blocked by washing in Tris-buffer containing $7.5 \%$ sucrose, followed by osmication overnight in $2 \% \mathrm{OsO}_{4}$ in the same buffer (without sucrose). Thereafter the specimens were dehydrated in a graded series of ethanol $(70,85,95$, $100 \%$; 10 min each) (Ladd, Burlington, VT, USA), and then embedded in LX medium. Semi-thin sections of $2 \mu \mathrm{m}$ were contrasted with toluidine blue and examined with a Leitz Aristoplan light microscope equipped with a Leitz orthomat $E$ photo camera. Ultrathin sections of $60 \mathrm{~nm}$ were cut with a diamond knife on a Reichert Jung Ultracut E ultramicrotome (Austria), mounted on formvar-coated copper grids, and stained with uranyl acetate and lead citrate. Samples were viewed on a Jeol 1200 EXII TEM at $80 \mathrm{kV}$ accelerating voltage. For quantitative control, FACS assay was performed as described above. The localization of HRP was revealed cytochemically by the following oxidation reaction:

$$
\begin{aligned}
\mathrm{HRP} & +\mathrm{H}_{2} \mathrm{O}_{2}+\mathrm{DAB} \rightarrow \mathrm{HRP}+2 \mathrm{H}_{2} \mathrm{O} \\
& + \text { oxidized DAB (brownish staining) }
\end{aligned}
$$

\section{Analysis of internalization mechanisms using the PI3K inhibitor wortmannin}

Wortmannin (Sigma-Aldrich N.V.) was dissolved at $200 \mu \mathrm{M}$ in DMSO, and stored as $7-\mu \mathrm{l}$ aliquots at $-20^{\circ} \mathrm{C}$. Wortmannin aliquots were thawed and added directly to $\mathrm{Mf} 4 / 4$ to achieve the final concentration indicated in each experiment. As wortmannin is photosensitive and unstable in aqueous solutions, it was routinely thawed, diluted, and added to cells within $10 \mathrm{~min}$.

\section{Acknowledgements}

We thank Dominique Jacobus, Barbara De Bondt, and Hubert Stevens for excellent technical assistance. We are grateful to Amin Bredan for copy editing the manuscript. This study was supported by Ghent University GOA Grant no. 12050502.

\section{References}

1. Kerr JF, Wyllie AH and Currie AR (1972) Apoptosis: a basic biological phenomenon with wide-ranging implications in tissue kinetics. Br. J. Cancer 26: 239-257.

2. Savill J, Dransfield I, Hogg N and Haslett C (1990) Vitronectin receptormediated phagocytosis of cells undergoing apoptosis. Nature 343: 170-173.

3. Savill J, Hogg N, Ren Y and Haslett C (1992) Thrombospondin cooperates with CD36 and the vitronectin receptor in macrophage recognition of neutrophils undergoing apoptosis. J. Clin. Invest. 90: 1513-1522.

4. Brown S, Heinisch I, Ross E, Shaw K, Buckley CD and Savill J (2002) Apoptosis disables CD31-mediated cell detachment from phagocytes promoting binding and engulfment. Nature 418: 200-203.

5. Ogden CA, deCathelineau A, Hoffmann PR, Bratton D, Ghebrehiwet B, Fadok VA and Henson PM (2001) C1q and mannose binding lectin engagement of cell surface calreticulin and CD91 initiates macropinocytosis and uptake of apoptotic cells. J. Exp. Med. 194: 781-795.

6. Gershov D, Kim S, Brot N and Elkon KB (2000) C-Reactive protein binds to apoptotic cells, protects the cells from assembly of the terminal complement 
components, and sustains an antiinflammatory innate immune response: implications for systemic autoimmunity. J. Exp. Med. 192: 1353-1364

7. Hanayama R, Tanaka M, Miwa K, Shinohara A, Iwamatsu A and Nagata S (2002) Identification of a factor that links apoptotic cells to phagocytes. Nature 417: 182-187.

8. Fadeel B and Kagan VE (2003) Apoptosis and macrophage clearance of neutrophils: regulation by reactive oxygen species. Redox. Rep. 8 : 143-150.

9. Fadok VA, Bratton DL, Konowal A, Freed PW, Westcott JY and Henson PM (1998) Macrophages that have ingested apoptotic cells in vitro inhibit proinflammatory cytokine production through autocrine/paracrine mechanisms involving TGF-beta, PGE2, and PAF. J. Clin. Invest. 101: 890-898.

10. Savill J, Dransfield I, Gregory C and Haslett C (2002) A blast from the past: clearance of apoptotic cells regulates immune responses. Nat. Rev. Immunol. 2: 965-975.

11. Gao Y, Herndon JM, Zhang H, Griffith TS and Ferguson TA (1998) Antiinflammatory effects of CD95 ligand (FasL)-induced apoptosis. J. Exp. Med. 188: 887-896.

12. Chen W, Frank ME, Jin W and Wahl SM (2001) TGF-beta released by apoptotic $T$ cells contributes to an immunosuppressive milieu. Immunity 14 715-725.

13. Denecker G, Vercammen D, Steemans M, Vanden Berghe T, Brouckaert G Van Loo G, Zhivotovsky B, Fiers W, Grooten J, Declercq W and Vandenabeele $P(2001)$ Death receptor-induced apoptotic and necrotic cell death: differential role of caspases and mitochondria. Cell. Death Differ. 8: 829-840.

14. Proskuryakov SY, Konoplyannikov AG and Gabai VL (2003) Necrosis: a specific form of programmed cell death? Exp. Cell Res. 283: 1-16.

15. Krysko O, De Ridder L and Cornelissen M (2004) Phosphatidylserine exposure during early primary necrosis (oncosis) in JB6 cells as evidenced by immunogold labeling technique. Apoptosis 9: 495-500.

16. Hirt UA and Leist M (2003) Rapid, noninflammatory and PS-dependent phagocytic clearance of necrotic cells. Cell. Death Differ. 10: 1156-1164.

17. Brouckaert G, Kalai M, Krysko DV, Saelens X, Vercammen D, Ndlovu M, Haegeman G, D'Herde K and Vandenabeele P (2004) Phagocytosis of necrotic cells by macrophages is phosphatidylserine dependent and does not induce inflammatory cytokine production. Mol. Biol. Cell 15: 1089-1100.

18. Swanson JA and Watts C (1995) Macropinocytosis. Trends Cell Biol. 5: 424-428.

19. Hoffmann PR, deCathelineau AM, Ogden CA, Leverrier Y, Bratton DL, Daleke DL, Ridley AJ, Fadok VA and Henson PM (2001) Phosphatidylserine (PS) induces PS receptor-mediated macropinocytosis and promotes clearance of apoptotic cells. J. Cell Biol. 155: 649-659.

20. Krysko DV, Brouckaert G, Kalai M, Vandenabeele P and D'Herde K (2003) Mechanisms of internalization of apoptotic and necrotic L929 cells by a macrophage cell line studied by electron microscopy. J. Morphol. 258 : 336-345.

21. Hart SP, Smith JR and Dransfield I (2004) Phagocytosis of opsonized apoptotic cells: roles for 'old-fashioned' receptors for antibody and complement. Clin. Exp. Immunol. 135: 181-185.

22. Steinman RM and Cohn ZA (1972) The interaction of soluble horseradish peroxidase with mouse peritoneal macrophages in vitro. J. Cell Biol. 55: 186204.

23. Steinman RM, Silver JM and Cohn ZA (1974) Pinocytosis in fibroblasts. Quantitative studies in vitro. J. Cell Biol. 63: 949-969.

24. Norbury CC, Chambers BJ, Prescott AR, Ljunggren HG and Watts C (1997) Constitutive macropinocytosis allows TAP-dependent major histocompatibility complex class I presentation of exogenous soluble antigen by bone marrowderived dendritic cells. Eur. J. Immunol. 27: 280-288.

25. Leverrier $Y$ and Ridley AJ (2001) Requirement for Rho GTPases and PI 3kinases during apoptotic cell phagocytosis by macrophages. Curr. Biol. 11: 195-199.

26. Hu B, Punturieri A, Todt J, Sonstein J, Polak T and Curtis JL (2002) Recognition and phagocytosis of apoptotic $T$ cells by resident murine tissue macrophages require multiple signal transduction events. J. Leukoc. Biol. 71: 881-889.

27. Goldman R and Bursuker I (1976) Differential effects of lectins mediating erythrocyte attachment and ingestion by macrophages. Exp. Cell Res. 103: 279-294.

28. Dini L, Pagliara P and Carla EC (2002) Phagocytosis of apoptotic cells by liver: a morphological study. Microsc. Res. Tech. 57: 530-540.
29. Geiser M (2002) Morphological aspects of particle uptake by lung phagocytes. Microsc. Res. Tech. 57: 512-522.

30. Monks J, Rosner D, Jon Geske F, Lehman L, Hanson L, Neville MC and Fadok VA (2005) Epithelial cells as phagocytes: apoptotic epithelial cells are engulfed by mammary alveolar epithelial cells and repress inflammatory mediator release. Cell. Death Differ. 12: 107-114.

31. Griffin Jr FM, Griffin JA, Leider JE and Silverstein SC (1975) Studies on the mechanism of phagocytosis. I. Requirements for circumferential attachment of particle-bound ligands to specific receptors on the macrophage plasma membrane. J. Exp. Med. 142: 1263-1282.

32. Griffin Jr FM, Griffin JA and Silverstein SC (1976) Studies on the mechanism of phagocytosis. II. The interaction of macrophages with anti-immunoglobulin IgGcoated bone marrow-derived lymphocytes. J. Exp. Med. 144: 788-809.

33. Swanson JA and Baer SC (1995) Phagocytosis by zippers and triggers. Trends Cell Biol. 5: 89-93.

34. Giles KM, Hart SP, Haslett C, Rossi AG and Dransfield I (2000) An appetite for apoptotic cells? Controversies and challenges. Br. J. Haematol. 109: $1-12$.

35. Garcia-Porrero JA, Colvee E and Ojeda JL (1984) The mechanisms of cell death and phagocytosis in the early chick lens morphogenesis: a scanning electron microscopy and cytochemical approach. Anat. Rec. 208: 123-136.

36. Torii I, Morikawa S, Nagasaki M, Nokano A and Morikawa K (2001) Differential endocytotic characteristics of a novel human B/DC cell line HBM-Noda: effective macropinocytic and phagocytic function rather than scavenging function. Immunology 103: 70-80.

37. Follett EA and Goldman RD (1970) The occurrence of microvilli during spreading and growth of BHK21-C13 fibroblasts. Exp. Cell Res. 59: 124-136.

38. Erickson CA and Trinkaus JP (1976) Microvilli and blebs as sources of reserve surface membrane during cell spreading. Exp. Cell Res. 99: 375-384.

39. Dini L, Ruzittu M, Carla EC and Falasca L (1998) Relationship between cellular shape and receptor-mediated endocytosis: an ultrastructural and morphometric study in rat Kupffer cells. Liver 18: 99-109.

40. Bruehl RE, Springer TA and Bainton DF (1996) Quantitation of L-selectin distribution on human leukocyte microvilli by immunogold labeling and electron microscopy. J. Histochem. Cytochem. 44: 835-844.

41. Berlin C, Bargatze RF, Campbell JJ, von Andrian UH, Szabo MC, Hasslen SR, Nelson RD, Berg EL, Erlandsen SL and Butcher EC (1995) alpha 4 integrins mediate lymphocyte attachment and rolling under physiologic flow. Cell 80 : 413-422.

42. Erlandsen SL, Hasslen SR and Nelson RD (1993) Detection and spatial distribution of the beta 2 integrin (Mac-1) and L-selectin (LECAM-1) adherence receptors on human neutrophils by high-resolution field emission S.E.M. J. Histochem. Cytochem. 41: 327-333.

43. Kalai M, Van Loo G, Vanden Berghe T, Meeus A, Burm W, Saelens X and Vandenabeele $P$ (2002) Tipping the balance between necrosis and apoptosis in human and murine cells treated with interferon and dsRNA. Cell. Death Differ. 9: 981-994.

44. Saelens X, Festjens N, Parthoens E, Vanoverberghe I, Kalai M, van Kuppeveld $F$ and Vandenabeele $P(2005)$ Protein synthesis persists during necrotic cell death. J. Cell Biol. 168: 545-551.

45. Wiegand UK, Corbach S, Prescott AR, Savill J and Spruce BA (2001) The trigger to cell death determines the efficiency with which dying cells are cleared by neighbours. Cell. Death Differ. 8: 734-746.

46. Nauta AJ, Trouw LA, Daha MR, Tijsma O, Nieuwland R, Schwaeble WJ, Gingras AR, Mantovani A, Hack EC and Roos A (2002) Direct binding of C1q to apoptotic cells and cell blebs induces complement activation. Eur. J. Immunol. 32: 1726-1736.

47. Nauta AJ, Raaschou-Jensen N, Roos A, Daha MR, Madsen HO, BorriasEssers MC, Ryder LP, Koch C and Garred P (2003) Mannose-binding lectin engagement with late apoptotic and necrotic cells. Eur. J. Immunol. 33: 28532863.

48. Cocco RE and Ucker DS (2001) Distinct modes of macrophage recognition for apoptotic and necrotic cells are not specified exclusively by phosphatidylserine exposure. Mol. Biol. Cell 12: 919-930.

49. Shpetner H, Joly M, Hartley D and Corvera S (1996) Potential sites of PI-3 kinase function in the endocytic pathway revealed by the PI-3 kinase inhibitor, wortmannin. J. Cell Biol. 132: 595-605.

50. Peppelenbosch MP, DeSmedt M, Pynaert G, van Deventer SJ and Grooten J (2000) Macrophages present pinocytosed exogenous antigen via MHC class I 
whereas antigen ingested by receptor-mediated endocytosis is presented via MHC class II. J. Immunol. 165: 1984-1991.

51. Barker RN, Erwig LP, Hill KS, Devine A, Pearce WP and Rees AJ (2002) Antigen presentation by macrophages is enhanced by the uptake of necrotic, but not apoptotic, cells. Clin. Exp. Immunol. 127: 220-225.

52. Vercammen D, Brouckaert G, Denecker G, Van de Craen M, Declercq W, Fiers W and Vandenabeele $P$ (1998) Dual signaling of the Fas receptor: initiation of both apoptotic and necrotic cell death pathways. J. Exp. Med. 188: 919-930.
53. Desmedt M, Rottiers P, Dooms H, Fiers W and Grooten J (1998) Macrophages induce cellular immunity by activating Th1 cell responses and suppressing Th2 cell responses. J. Immunol. 160: 5300-5308.

54. Cvetanovic M and Ucker DS (2004) Innate immune discrimination of apoptotic cells: repression of proinflammatory macrophage transcription is coupled directly to specific recognition. J. Immunol. 172: 880-889.

55. Vanden Berghe T, Denecker G, Brouckaert G, Vadimovisch Krysko D, D'Herde $\mathrm{K}$ and Vandenabeele $\mathrm{P}$ (2004) More than one way to die: methods to determine TNF-induced apoptosis and necrosis. Methods Mol. Med. 98: 101-126.

Supplementary Information accompanies the paper on Cell Death and Differentiation website (http://www.nature.com/cdd) 